Session 2249

\title{
Design a Lab Manual of Plastic Materials Testing Course Using Multimedia
}

\author{
Seung Kim and James Scudder \\ Manufacturing and Mechanical Engineering Technology/Packaging Science \\ Rochester Institute of Technology
}

\section{INTRODUCTION}

Education technology is on the brink of a new era based on the rapid advancement in computer and communication technologies. For the past several years, computer technology has been used in education to prepare students for tomorrow's technological changes. The paradigm of teaching engineering technology courses has been challenged by making undergraduate experiences more relevant to the needs of the manufacturing industry and global competition. Thus, the use of the computer technology has been an important tool to meet such needs for the improvement of engineering technology education.

In distance education, a multimedia-based teaching tool has the potential to meet changing educational needs: particularly, the student's needs to choose his/her own time, place, and study style. A number of universities have responded to the trend in the use of computer technology in education $^{1-4}$. More significantly, multimedia technology has been exploited as an advanced tool in distance education. The value of such multimedia-based teaching tools to the distance education lies not only in supporting fundamental functions in education, but also in transforming traditional teaching mechanisms to computer-screen-based interactive structures.

The goals in the development of the multimedia-based laboratory manual in the Manufacturing and Mechanical Engineering Technology (MMET) programs are to provide fundamental information and to visualize laboratory practices in plastics testing for distance-learning students. This paper presents the development of a multimedia-based laboratory manual in plastics testing in the distance-learning program in the MMET Department at R.I.T. The paper also considers some change needed to improve teaching quality by adapting asynchronous interactions. 


\section{NEEDS OF MULTIMEDIA TOOL}

Plastic materials have become irreplaceable and are used as adhesives, textiles, packaging, foams, elastomers, biomedical devices, optic elements, composites, and engineering plastics. Such potential applications of plastics are so limitless that there is an exciting future in the plastics industry for engineering technology students in the MMET programs. Plastics technology is a multidisciplinary subject dealing with materials and properties, testing and characterization, production and process control, parts and mold design, assembly and finishing, process automation and simulation, prototyping, and quality control.

Mechanical Engineering Technology Lab II primarily focuses on understanding principles of plastics testing in the MMET programs. This course provides an opportunity to students how plastics are important materials and which testing methods are appropriate for the improvement and development of plastic parts or products. Recently, the use of multimedia tools in the development of course materials in engineering technology curricula has shown a promise to produce graduates who can quickly become effective member in various fields of manufacturing. Thus, a multimedia approach in teaching a laboratory-oriented course will meet such a challenge to fulfill the needs of the future in the field of engineering technology.

For the past several quarters, the number of nontraditional students enrolled in the distancelearning program, who need to acquire knowledge in plastics testing and technology, has increased. However, the nontraditional students have faced more struggles in studying laboratory-oriented courses than the traditional students. I find that some traditional approaches, such as videotaped lecture and printed lab manual, are failing to meet the challenge in teaching the nontraditional students in distance learning program. A large part of the problem is lack of preparation for the course and their lack of access to lab equipment. The development of a multimedia-based lab manual will provide an efficient approach to convey fundamentals in plastics testing through multimedia tools for nontraditional students.

The objective of the development of the multimedia-based laboratory manual is to provide a proper preparation in fundamentals of plastics testing for students in the distance-learning program using computer technology. Thus, the students will be prepared to deal with inevitable future changes in modern plastic technology.

\section{DESIGN GOALS OF MUTIMEDIA-BASED LAB MANUAL}

The development goal of a multimedia-based lab manual is to provide quality education for distance-learning students. Quality in this context requires a high standard in teaching, effectiveness in conveying desired information, accommodation of diversity in student learning style, support in independent study, and consistency in the delivery of course materials.

The design of this multimedia-based lab manual will treat both theoretical and practical subjects in the fundamentals of plastics testing. In order to better communicate the theoretical subjects in plastics testing laboratory, the structure of the lab manual should address the following topics: (1) a fundamental background in plastics testing, (2) testing equipment and operations, (3) analysis technique and report format, and (4) software tools for calculation and simulation. Thus, 
the development of the multimedia-based lab manual will provide an efficient approach to convey fundamentals in plastics testing through multimedia tools for nontraditional students.

\section{INTERACTIVE MULTIMEDIA LABORATORY MANUAL (IMLM)}

There are two ways in which "Interactive Multimedia Lab Manual (IMLM)" differs from a traditional-printed lab manual: 1) unlike a bounded collection of papers of a type-written lab manual, multimedia-based lab manual can combine words, mathematical equations, simulation, pictures, sound, animation, and video for publishing information. 2) Most importantly and unlike any traditional-publishing media, a multimedia-based lab manual can respond to interaction from the readers (students).

The IMLM allows students to move through the computer-based document in the way that is relevant to them, to jump specific places and pages, get further details of information, visualize laboratory experiments by clicking buttons on a mouse. It also allows an instructor to keep track of where the students have traveled. However, a multimedia tool needs to create a digital version of the same kinds of documents as the instructor would ordinarily create on paper with extra dimensions of multimedia and interactivity. In this way, the interactive multimedia lab manual is one of the exciting forms of communication available to educators.

\section{PREPARATION}

Preparation and planning are not wasted efforts when creating a multimedia project, but instead, they can save valuable time later on. Prior to starting the design of a multimedia publication, the theme and the goals of the project should be decided. It is useful to plan the pages of the publication on a storyboard. The storyboard is a layout of the basic contents of the publication. Also, the format and the distribution method of the multimedia publication should be considered. The format and contents of the storyboard can be created on paper. When the project starts to create the contents with author ware, all things should be considered in advance.

\section{PROTOTYPE}

The prototype "Interactive Multimedia Laboratory Manual (IMLM)," consists of five Chapters: 1) the index and contents of the IMLM, 2) the information of course and preparation, 3) the description of laboratory experiments, 4) the "PDF" formatted traditional lab manual, and 5) the presentations and topics from former students. Within each Chapter, several pages of the subjected topics are storyboarded using a multimedia format. Thus, students can investigate basic principles of materials testing and visual results of the experiments with movie clips, slides, and sounds.

For example, the students can learn bout equipment, preparation, theory, procedures, and experimental results in tensile testing of plastics by clicking mouse. Also, more detailed information is included in "PDF" formatted files for further study; the traditionally published data and reports can be converted into digital information files in IMLM. Using such a 
multimedia tool, the students can study facility, laboratory, equipment, and other resources for the lab activity, as if they are in a real materials laboratory at R.I.T.

Using a multimedia based lab manual, distance-learning students can be exposed to the concepts in plastics testing. Along with the use of the multimedia based lab manual, the students can reinforce their skills by attending hands-on laboratory sessions.

\section{PRODUCTIVITY GAINS}

The development of the interactive multimedia lab manual is specifically concerned with the following outcomes:

1) Comprehension: Improve comprehension of theoretical and technical concepts of plastics testing for distance learning students.

2) Motivation: Motivate students to master fundamentals in materials testing using a multimedia form of lab manual.

3) Effectiveness in Teaching: Add more materials (more than the normal amount of quarter course materials) including computation, analysis, and data.

\section{CONCLUSION}

In distance education, a multimedia-based teaching tool has the potential to meet changing educational needs: particularly, the needs for students to choose their own time, place, and study style. The development of a multimedia-based laboratory manual provides a proper preparation in fundamentals of plastics testing for students in distance learning program at R.I.T. Using an interactive multimedia laboratory manual, students will be prepared to deal with inevitable changes in modern plastic technology in the future.

\section{ACKNOWLEDGEMENT}

The development of the multimedia-based laboratory manual is supported by Provost's Productivity Grant at R.I.T.

\section{BIBLIOGRAPHY}

1. Poli, C. and Wolf, B., Design for Manufacturing Tutorials-a Multimedia Approach, 1996 ASEE Annual Conference Proceedings, Session 3263, 1999.

2. Suni, I.I., Ross, S.M., Rasmussen, D.H., and Babu, S.V., Development of a CD-ROM Thin Film Technologies: Usability, Assessment and Evaluation from a Student Perspective, 1996 ASEE Annual Conference Proceedings, Session 1626, 1996.

3. Abbanat, R.F., J.W. Honchell, J.W., Multimedia in Technology Education: Who is Going to Pay?, 1996 ASEE Annual Conference Proceedings, Session 2547, 1996. 
4. Neu, E.C., Computers and Overheads vs. Multimedia in the Classroom, 1996 ASEE Annual Conference Proceedings, Session 2220, 1996.

\section{SEUNG KIM}

Dr. Seung H. Kim is currently an Assistant Professor in the Manufacturing and Mechanical Engineering Technology/Packaging Science Department at Rochester Institute of Technology. He graduated from Hanyang University, Seoul, South Korea, in 1979 with B.S. in Ceramics Engineering. He received his M.S. and Ph.D. in Materials Engineering at the University of Illinois at Chicago in 1989 and 1993, respectively. He worked in semiconductor manufacturing for seven years.

James F. Scudder, P.E.

Professor James Scudder is a Professor and Program Chair of Electrical/Mechanical Engineering Technology at R.I.T. He received his B.M.E. and M.E. at Cornell University in 1958 and 1988, respectively. He is a Professional Engineer in New York State and worked in Camera Design, Engineering Computer Support, and Computer Aided Drafting Support at Eastman Kodak Co. for 28 years. 